asthma than other forms of exercise, possibly because there is less shaking of the chest. Fitch and his colleagues in Australia have recently reported ${ }^{5}$ the effects of training on 46 asthmatic children who swam $3608 \mathrm{~km}$ in five months. Their training programme started with three sessions a week and was gradually increased to five one-hour sessions. This programme had no adverse effects and was enthusiastically accepted by both the children and their parents; and it led to a decrease in protective attitudes and a sense of liberation from previous restrictions. Non-specific indicators of physical fitness improved, but even more important was a fall in the need for drugs and a reduction in asthmatic symptom scores. Swimming may be recommended as part of the treatment for children with asthma.

These two studies reflect the modern intensive approach to the investigation and treatment of childhood asthma. Such children can no longer be regarded as "delicate" or "nervous": they suffer from an organic disease requiring full investigation by a paediatrician; they also need encouragement and help to develop their strong desire to participate and compete in activities at which they can excel.

${ }^{1}$ Sarsfield, J K, et al, Archives of Disease in Childhood, 1976, 51, 186.

${ }^{2}$ Berg, T, Bennich, H, and Johansson, S G O, International Archives of Allergy, 1971, 40, 770.

${ }^{3}$ Jones, R S, Buston, $\mathrm{M} \mathrm{H}$, and Wharton, M J, British fournal of Diseases of the Chest, 1962, 56, 78 .

${ }^{4}$ Blackhall, M I, and Jones, R S, in Disodium Cromoglycate in Allergic Airways Disease, ed J Pepys and A W Frankland, p 63. London, Butterworths, 1970.

${ }^{5}$ Fitch, K D, Morton, A R, and Blanksby, B A, Archives of Disease in Childhood, 1976, 51, 190.

${ }^{6}$ Fitch, K D, and Morton, A R, British Medical fournal, 1971, 4. 577.

\section{Vaccination against swine influenza}

Vaccination of the entire population of the USA against swine influenza is a bold undertaking. That was the recommendation adopted by President Ford ${ }^{1}$ after the recent outbreak of influenza ${ }^{2}$ among army recruits at Fort Dix, New Jersey, which was due partly to a virus closely similar to the swine virus believed to have caused the pandemic of 1918. Control of pandemic influenza in the USA would be an achievement deserving of the greatest effort, but the success of this American enterprise is uncertain.

Three main considerations appear to have influenced the American decision. Firstly, the swine influenza virus has changed from being almost entirely a pig pathogen. The virus is thought to have adapted itself to pigs during the 1918 pandemic, and, though there have been rare human cases since, they have been mostly subclinical and in persons in close contact with pigs; until the Fort Dix outbreak there had been no recognised case-to-case transmission. In the outbreak there were 11 proved cases of clinical influenza due to the virus $^{3}$ with one fatality, and serological surveys showed that about 500 more infections had occurred, though many of these had been subclinical. The New Jersey virus, therefore, while retaining the surface antigens of the swine virus, has acquired or perhaps reacquired the ability to spread from person to person and to cause disease in healthy adults. This evidence has been supported by findings at the Common Cold Research Centre at Salisbury, where some years ago Beare and his colleagues infected volunteers with one of two swine isolates; they were found to be of low infectivity and caused little or no clinical illness. ${ }^{4}$ They have now examined the effect of the New Jersey virus, and though it was judged to be of low virulence it was able to cause influenza. ${ }^{5}$

Secondly, most people under 50 years of age in the USA and elsewhere have no serological evidence of immunity to the New Jersey virus ${ }^{6}$; they must be regarded as highly susceptible. The New Jersey virus could be considered as a new example of antigenic shift, and when these have been seen in the past (as with the Asian virus of 1957 and the Hong Kong virus of 1968) severe pandemics have followed. But it is also difficult to discount the fear that the swine virus may be more dangerous for man than other influenza viruses because the pandemic of 1918 was unusually devastating: it killed more people in a few months than the Great War in nearly five years. ${ }^{7}$

Thirdly, sufficient warning has been given of a possible pandemic. For the first time there is the opportunity to prepare large amounts of vaccine in the USA and by vigorous effort to vaccinate most of the population before the winter.

No other country has proposed mass vaccination, though in Canada the aim is to vaccinate widely-perhaps half the population. ${ }^{\gamma}$ At a meeting of experts, including those of the USA, held by the World Health Organisation in April 1976 three possible policies were considered to be justified for countries that had the means: ${ }^{9}$ to stockpile vaccine so that it would be available in the event of a pandemic; to incorporate the New Jersey virus into standard influenza vaccine containing the A Victoria and B Hong Kong strains that are otherwise likely to be prevalent next winter; and to administer a monovalent vaccine. Why has no other country opted for mass vaccination? There are convincing reasons, apart from any lack of money and facilities which might preclude such an effort.

The swine virus may have changed, but it has not so far shown unusual virulence for man. Though it resulted in one death, the New Jersey swine virus infections in the Fort Dix outbreak were no more severe than those due to the A/Victoria virus which also caused infections despite the fact that the recruits should have had some antibody to viruses related to A Victoria but virtually none to the swine virus. Conditions in recruit camps favour epidemic spread, but the swine outbreak lasted only about five weeks, whereas A/Victoria infections persisted for a further several weeks. There was no spread outside the camp, except for serological evidence that transmission may have occurred in the household of one of the recruits. ${ }^{10}$ The epidemiological data, and Beare's studies, suggest that the New Jersey virus, at least at present, is rather less virulent than most wild influenza $A$ viruses.

Though many people under 50 are likely to be susceptible to the New Jersey virus, most of those over this age have serum antibodies against its haemagglutinin at levels compatible with protection..$^{112}$ Resistance of this sector of the population could well damp down the impact of an epidemic, since it is the elderly who usually suffer the most serious effects of influenza (though admittedly a similar pattern of immunity might have accounted for the unusual mortality of the 1918 pandemic, which struck down so many young adults ${ }^{7}$ ).

Influenza on its own may prove fatal, but the complication of bacterial pneumonia has often been implicated as a major factor in the mortality accompanying epidemics. Bacterial infection can nowadays be treated with antimicrobials, and these have lowered influenza mortality. ${ }^{13}$ In this respect we are in a better position than in 1918 .

A swine influenza pandemic, if it does come, may not do so this year. A population given a single dose of vaccine in the 
autumn of 1976 could lose much of its protection by the winter of 1977-8, and it might then be hard to persuade people to accept another injection when the first turned out not to have been necessary. Moreover, previous pandemics have attacked countries in the Southern Hemisphere and the Far East before Europe and North America, and it is therefore reasonable to postpone decisions on widespread vaccination while keeping the swine virus under careful observation.

The view in the USA seems to be that it is better to risk money than health, ${ }^{14}$ but if there is no pandemic this winter there may well be other than monetary losses. When nearly 200 million people are vaccinated there could be a measurable number of severe allergic side effects which would not be balanced by tangible benefit. There could also be public loss of faith in influenza vaccine, which might extend to other vaccines. If a pandemic does appear, but not until 1977 or 1978 , it could find the American people less well protected than it is hoped they will be this coming winter. The vigour and determination of the American advisers are impressive, and they may be proved right, but the approach adopted by the Department of Health and Social Security ${ }^{15}$ seems likely to be a more responsible use of our own resources. Careful surveillance will be maintained to detect any appearance of the virus in Britain, and the results of similar work throughout the world will be closely watched. A New Jersey vaccine is being manufactured and the antigen will be incorporated in the standard influenza vaccine; trials are being made to establish the dose necessary to immunise people of different ages. In addition, as an extra precaution, a basic reserve of $\mathrm{A}$ New Jersey vaccine is to be established.

1 Weinstein, L, New England fournal of Medicine, 1976, 294, 1058.

2 British Medical fournal, 1976, 1, 730.

${ }^{3}$ US Department of Health, Education and Welfare, Morbidity and Mortality Weekly Report, 1976, 25, 55.

${ }^{4}$ Beare, A S, et al, Lancet, 1971, 1, 305.

5 Beare, A S, Lancet, 1976, 2, 4.

6 World Health Organisation, Weekly Epidemiological Record, 1976, 51, 134.

${ }^{7}$ Ministry of Health, Report on the Pandemic of Influenza 1918-19. London, HMSO, 1920.

${ }^{8}$ Lancet, 1976, 1, 921.

9 World Health Organisation, Weekly Epidemiological Record, 1976, 51, 123.

10 US Department of Health, Education and Welfare, Morbidity and Mortality Weekly Report, 1976, 25, 92.

${ }^{11}$ Houseworth, W J, and Spoon, M M, American fournal of Epidemiology, $1971,94,348$.

12 Schoenbaum, S C, et al, American fournal of Epidemiology, 1976, 103, 166.

13 Collins, S D, and Lehmann, J L, Public Health Reports, Washington, 1957, 72, 771.

14 Boffey, P M, Science, 1976, 192, 636

15 Lancet, 1976, 1, 1252.

\section{Tuberculosis in corticosteroid-treated asthmatics}

In the early days of corticosteroids fears were often expressed of reactivation of quiescent tuberculosis or of the development of tuberculosis in tuberculin-positive people with no evidence of clinical disease. Whenever a patient taking corticosteroids developed overt tuberculosis, these two events tended to be regarded as causally related.

As experience accumulated in chest clinics it became apparent that corticosteroid treatment was not important in precipitating tuberculosis. Surveying the experience of physicians in 50 British chest clinics, Mayfield ${ }^{1}$ found that of 11668 new cases of tuberculosis in 1959 and 1960 in only 32 was there a history of corticosteroid treatment at the time or within 6 months of diagnosis. Within the same period in these 50 clinics there were only 10 instances of reactivation of old tuberculosis in patients on corticosteroid treatment.

In' 1952 (a time when corticosteroids were being used increasingly in treatment) isoniazid came into use against tuberculosis. Its high activity against tubercle bacilli, its remarkably low toxicity, and the rarity of hypersensitivity reactions in comparison with other antituberculosis drugs led to widespread advocacy of its use in prophylaxis in persons thought to be at high risk. This view has been more widespread in the United States than in Britain. In $1965^{2}$ and $1967^{3}$ the American Thoracic Society gave a wide range of indications for such prophylaxis, suggesting that anyone put on corticosteroids who had a positive tuberculin test to $5 \mathrm{TU}$ should receive $300 \mathrm{mg}$ of isoniazid daily. Nevertheless, in $1970^{4}$ it sounded a note of caution since in those receiving isoniazid prophylaxis subclinical hepatotoxicity was more frequent than had been expected and occasionally peripheral neuropathy and hypersensitivity reactions occurred.

How big is the risk ? Assessment of the chance of reactivation or development of tuberculosis because of long-term corticosteroid treatment of another disease is complicated by the difficulty of defining a comparable group of patients with similar diseases not so treated. Smyllie and Connolly ${ }^{5}$ made a retrospective comparison of 550 patients treated at the Brompton Hospital with corticosteroids and 499 matched so far as possible for disease, age, sex, and year of entry into hospital followed for periods ranging from 18 months to 7 years. In the corticosteroid group there was one new case and none of reactivation of old tuberculosis; and in the control group, one new case and one reactivation. It was not routine policy to give antituberculosis drugs to patients with presumably healed old tuberculosis, and thus there was no evidence that corticosteroid treatment encouraged the development of tuberculosis. Similarly, Lieberman et $a l^{6}$ observed no reactivations of tuberculosis among 50 asthmatic patients in a study of the complications of corticosteroid treatment.

Schatz et $a l^{7}$ have recently reported a study of tuberculosis and tuberculin sensitivity in 132 corticosteroid-treated asthmatics. Encouraged by reports of a low risk, they refrained from the policy of isoniazid prophylaxis for tuberculinpositive subjects officially advocated in the United States. Nevertheless, during a total of 620 treatment-years, there was no instance of the development of active tuberculosis. One patient who had been treated for tuberculosis in the past received isoniazid during the first year only of five and a half years of treatment with a usual dosage of 50 to $60 \mathrm{mg}$ of prednisone on alternate days. Ten others with focal calcifications suggesting healed tuberculosis or other granulomatous infection were not given isoniazid. Tuberculin tests during corticosteroid treatment gave positive reactions to $5 \mathrm{TU}$ in $28 \%$ of patients, and to $250 \mathrm{TU}$ in $42 \%$ of those not reacting to $5 \mathrm{TU}$. As would be expected, the proportions of reactors increased with age. Among patients on daily corticosteroid treatment the proportion reacting to $5 \mathrm{TU}$ was negatively correlated with dosage, suggesting depression of reactivity by corticosteroid; there was no correlation among those reacting to $250 \mathrm{TU}$. These observations are in keeping with the finding of Citron and Scadding ${ }^{8}$ that the effect of cortisone on tuberculin reactions varies with the degree of tuberculin sensitivity, reactions to small doses of tuberculin in persons of high sensitivity being inhibited or much diminished, while those in persons of low sensitivity induced only by $100 \mathrm{TU}$ or more $\vec{\Rightarrow}$

\section{है}

\section{๔} . $\overrightarrow{0}$ . 